\title{
Summarizing and Communicating on Survival Data According to the Audience: A Tutorial on Different Measures Illustrated with Population-Based Cancer Registry Data [Corrigendum]
}

Belot A, Ndiaye A, Luque-Fernandez MA, et al. Clin Epidemiol. 2019;11:53-65.

Page 57, Number of life years lost (NLYL) section, left column, the sentence "where the quantity $1-F_{P}(t)$ can be replaced by $S_{P}(t)$, ie, the classical survival function using the population mortality rates $\lambda_{\mathrm{P}}$ " placed immediately after equation 14 indicates that the quantity $1-F_{P}(t)$ could be replaced by $S_{P}(t)$. This is wrong as the one-to-one relation- ship between hazard and risk applies only in all-cause mortality setting but not in competing risks settings (such as the cause-specific or relative survival setting). Indeed, $F_{P}$ $(t)$ depends on both hazards (cancer and other causes) through the overall survival $\mathrm{S}(t)$.

The authors therefore request the reader to ignore this sentence and apologize for this error.

\section{Publish your work in this journal}

Clinical Epidemiology is an international, peer-reviewed, open access, online journal focusing on disease and drug epidemiology, identification of risk factors and screening procedures to develop optimal preventative initiatives and programs. Specific topics include: diagnosis, prognosis, treatment, screening, prevention, risk factor modification, systematic reviews, risk \& safety of medical interventions, epidemiology \& biostatistical methods, and evaluation of guidelines, translational medicine, health policies \& economic evaluations. The manuscript management system is completely online and includes a very quick and fair peer-review system, which is all easy to use. 